\title{
LA SENSIBILIDAD DE LA VERDAD
}

\author{
María Antonia Labrada \\ Universidad de Navarra
}

Resumen: En este artículo se analiza la dialéctica entre sensibilidad y concepto presente en el libro de Inciarte Cultura y verdad. Esta dialéctica se añade a la existente entre objetividad y subjetividad, y el que y el cómo, en el análisis que hace el autor de la relación entre cultura y fe.

Palabras clave: Fernando Inciarte, Sensibilidad. Razón práctica. Forma. Fin. Fe. Arte. Moral.

\section{The Sensitivity of Truth}

Abstract: This article analyzes the dialectic between sensitivity and concept present in the book of Inciarte Culture and truth. This dialectic adds to these two: between objectivity and subjectivity, and "what" and "how", which articulate, according to the author, the relationship between culture and faith

Keywords: Fernando Inciarte, Sensitivity. Practical reason. Form. Aim. Faith. Art. Moral.

Recibido: 6/4/2017 Aceptado: 10/6/2017

Me propongo en este artículo analizar la dialéctica entre sensibilidad y concepto presente en el libro de Inciarte Cultura y verdad. Esta dialéctica se añade a la existente entre objetividad y subjetividad, y el qué y cómo en el análisis que se hace en el libro de la relación entre cultura y fe.

En el texto de referencia para esta jornada científica afirma Lourdes Flamarique que "asistimos a una repetida exigencia de verdad en el discurso 
político, cultural y artístico, lo que supone un abandono de la condición postmoderna en la literatura, el arte y la filosofía. A ello se añade el combate del islamismo radical contra la cultura occidental. Todo ello empieza a dar visibilidad a la presencia de lo absoluto como elemento constitutivo de toda formulación de lo relativo, también de lo cultural".

Como mantiene Inciarte, en la filosofía, la vida, la cultura, el arte y la fe nos jugamos todo porque se pone en juego la verdad. Pero ¿cómo puede entenderse la recuperación de la verdad en la formulación de lo relativo - de lo cultural — dando prioridad a lo subjetivo, al cómo y a la sensibilidad?

En primer lugar advierte Inciarte que no está hablando de sensibilidad en su sentido emocional:

La palabra sensibilidad es aquí clave. Y es clave porque tiene que ver mucho, todo, con la cuestión en juego: arte, vida, cultura, realidad, religión fe. De algún modo estos términos —incluido el de sensibilidad — son sinónimos. Son sinónimos cuando no se toma, por ejemplo, la palabra sensibilidad en el sentido de tener simplemente una piel fina, de ser impresionable, o de ser susceptible [...]. La sensibilidad de la que aquí se trata no tiene nada que ver con la sensiblería (Inciarte, 2016: 48-50).

Una primera aproximación al significado que tiene aquí la palabra sensibilidad está en la cercanía que existe en inglés entre sensible y razonable, es decir, entre el sentido y el entendimiento:

La palabra sensibus no puede, en efecto, haber sido mejor elegida para nuestro propósito de llegar a una mayor claridad en la cuestión de las relaciones entre en- 
tendimiento y sensibilidad, entre lo objetivo y lo subjetivo —aun cuando esa claridad no sea definitiva ni pueda tal vez nunca serlo- . El verbo correspondiente a la actitud reflexiva o razonable (traer a la razón, proceder con sensatez) no significa un conocer que viene sólo de la cabeza, un conocimiento abstracto; significa un conocimiento con sede principalmente en el corazón (Inciarte, 2016:75).

La inclinación a la verdad como constitutivo de la sensibilidad tiene un carácter moral o de conocimiento práctico (praxis). La necesidad de cultivar esta forma de sensibilidad tiene que ver con una exigencia moral:

El cultivo de la sensibilidad puede llegar a ser, y muchas veces es, un requerimiento, entre otras cosas del amor a la verdad - un caso o exigencia de honradez intelectual y, por tanto, también moral (Inciarte, 2016: 95).

Nos encontramos, con lo que los clásicos denominaron praxis o conocimiento práctico, un tema que ha acompañado a Inciarte durante toda su trayectoria filosófica. En el capítulo cuarto de su libro El reto del positivismo lógico trata de esta cuestión.

La verdad práctica - a diferencia de la teórica - se ocupa del deber ser que como tal no existe de antemano ni tampoco está al margen o por encima de lo que se ocupa la verdad práctica:

El deber ser en que reside la verdad práctica no puede consistir ni en algo que ya existe de antemano, ni en algo completamente al margen, por encima o anterior a lo dado. El deber ser aparece aquí incluido en el ser, pero el ser en el que está incluido el deber ser no es un ser dado inerte que sólo pudiera ser constatado desde fuera, sino que es aquel ser del que Aristóteles dice que en los seres vivos consiste 
en vivir y en los seres vivos racionales en vivir conforme a razón, es decir, en praxis, en actuar racional (Inciarte, 1974: 174-175).

El deber ser está inserto en el ser de los seres vivos racionales y consiste en un vivir conforme a razón. La forma de actuar racional o conforme a razón no nace en un espacio, por decirlo así, teórico; nace con la vida buscando en las acciones más variadas el sentido - la verdad- que subyace. $Y$ ahí empieza la filosofía mezclada indisolublemente con la vida, con el estar entre las cosas, con los intereses, no al margen o con anterioridad a todo ello.

En el pensamiento de Inciarte anida la convicción que se vislumbra de un modo u otro en sus escritos de que el conocimiento práctico es condición de posibilidad del teórico y no al revés (como en ocasiones se entiende la verdad práctica). Esto no significa que la verdad teórica sea construida desde la praxis porque la acción práctica — como se verá más adelante- no tiene nada de constructo.

Pero hay otro asunto en el que me voy a detener ahora. Ese vivir conforme a razón que Aristóteles considera propio de los seres racionales y que funda la praxis reclama - como acción práctica - el discernimiento, la decisión y la libertad que explica el carácter moral de esas acciones. Traduciéndolo al tema que me ocupa: la sensibilidad a la verdad es una sensibilidad libre. Y ahí está la dificultad (teórica) del tema.

Hay otro escrito de Inciarte que puede iluminar esta cuestión. Se titula Sobre la libertad del intelecto, de la razón y de la voluntad. En este artículo se plantea si la libertad tiene como sujeto la voluntad o el entendimiento. 
La tesis de que la raíz de la libertad está en la voluntad (y no en el conocimiento), proviene de Duns Scoto que se aparta de la postura aristotélica:

Aristóteles considera que el intelecto carece en absoluto de naturaleza propia y es, por tanto, aunque Aristóteles no lo diga explícitamente, libre. El intelecto consiste exclusivamente en poder ser todas las cosas, hacerse con ellas, conocerlas. Para ello necesita estar precisamente libre de ellas (Inciarte, 1990: 289).

Con Duns Scoto la libertad cae por entero del lado de la voluntad y se desliga de esta raíz cognoscitiva; es más el intelecto aparece en él como algo natural y esto significa que está determinado a una y la misma cosa. Aparte del intelecto, está, la razón, pero Escoto considera que la voluntad es la única potencia racional:

Lo que hace pues Duns Scoto, es trasferir a la voluntad la libertad que correspondía al intelecto posible aristotélico. A pesar de la distancia cronológica que media entre ambos, ésta es exactamente la posición que todavía perdura en Kant. Lo único libre es la razón práctica o voluntad. La razón teórica o intelecto, en cambio, es, exactamente como en Duns Scoto, algo sometido al determinismo de la naturaleza, un trozo de esta misma o, por lo menos, aquello que da razón de la ilimitada determinación de lo natural, de su heterodeterminación (Inciarte, 1990: 289).

Si se transfiere a la voluntad la libertad que corresponde al entendimiento posible se compromete la libertad de la praxis, de la verdad práctica ligada a la sensibilidad y la tendencia. En la praxis - a diferencia del modo de proceder técnico- la simbiosis entre el fin y los medios se da de un modo 
indiscernible. En la técnica el fin es extrínseco a los medios pero en la praxis no puede serlo. Si no cabe la separación tampoco cabe sacrificar la actuación moral a un fin superior. El fin en la acción moral no es extrínseco a ella, no puede ser elegido por una voluntad pura desligada de cualquier tendencia o interés.

El fin es descubierto en la acción práctica como dado en la naturaleza racional que implica la libertad. ¿Cómo se conjuga lo dado por naturaleza y la libertad? ¿No es esta forma de vida racional monótona? El problema de la monotonía del vivir conforme a razón se resuelve con la consideración de que el descubrimiento del fin se produce en el discernimiento de los medios:

De este modo queda neutralizado el asomo de monotonía que acecha a toda concepción de la vida para la cual el fin supremo de la vida viene dado de antemano y siempre es el mismo. Pero que la forma de vida que hemos de seguir nos venga dada por naturaleza no implica uniformidad alguna. Eso sería el caso si el fin fuera puramente técnico y estuviera desligado de los medios. En este caso la única alternativa a la uniformidad sería la elección de la forma de vida que uno quiera llevar: la opción fundamental. Ello trae consigo notorios inconvenientes. $\mathrm{Ni}$ tan siquiera con la regla de la universalización o del imperativo categórico se puede evitar el admitir como válida la forma de vida del fanático nazi que sigue en sus trece después de descubrir que él mismo es judío. La elección del fin último puede significar como en este caso el fin de la moral. La elección del fin último no es la única alternativa para evitar la uniformidad. Más bien es un modo más de reducir la moral a técnica (Inciarte, 1990:288). 
Inciarte insiste en que el arte, la vida, el mundo o la cultura tienen que ver con esta forma de sensibilidad, con la síntesis entre la disposición, la tendencia y la verdad propia de la praxis en la que fines y medios no se pueden separar. Esto significa que la libertad anida en esta forma de actuación propia de una naturaleza racional, conforme a razón:

Si hay una verdad práctica, entonces verdad y utilidad o verdad e interés tienen que apoyarse mutuamente, porque sin ese mutuo apoyo no cabría extender el concepto de verdad a la vida, a la praxis y al interés (Inciarte, 1974: 170).

En esta forma de actuar no se busca desenmascarar supuestas verdades morales:

La verdad práctica se va constituyendo en el esfuerzo continuo para orientar nuestro comportamiento hacia un punto que no puede ser captado con independencia de esos mismos esfuerzos para dar con él (Inciarte, 1974: 175).

Llegados aquí no es preciso insistir en que lo decisivo en la praxis es la forma, el modo, la manera de proceder y que en esa forma de proceder se alumbra la verdad o el bien. Ciertamente con ello se adopta una perspectiva subjetiva o si se quiere relativa pero no arbitraria:

La pregunta teórica sobre que es el bien en sí (el fin) retrocede ante la pregunta sobre el cómo, la manera y por medio de qué surge surge el bien como algo que no existe de por sí, ni surgirá tampoco por sí mismo. Con esto —a pesar de la orientación práctica - no se elimina la pregunta teórica sobre qué sea el bien o el fin; por el contrario solo así se hace posible dar una respuesta a tal pregunta por- 
que para saber lo que tenemos que hacer tenemos que hacer lo que queremos saber (Inciarte, 1974: 173).

Si en la práctica — en el modo o la forma de proceder- se alumbra el fin, esto significa que éste (el fin) se revela en la forma, en la manera.

$\mathrm{El}$ interés temprano de Inciarte por la filosofía de Fichte quizá responda a otro modo de acercarse a esta misma cuestión.

En Fichte lo que se viene llamando la sensibilidad de la verdad (la praxis), está en el origen de toda la actividad intelectual y moral de la persona. En la Doctrina de la Ciencia se plantea una aproximación entre la sensibilidad y la verdad que es captada por la imaginación trascendental. Esta facultad es denominada por Fichte facultad moral originaria:

Por imaginación se entiende aquí otra vez, por supuesto, la trascendental y no la empírica. A diferencia de ésta, aquella no es una potencia sensible, sino una potencia que pende entre lo sensible y lo intelectual, y que en este su pender originario o trascendental constituye la condición de posibilidad de unión de la sensibilidad con la inteligencia o, lo que es igual, la condición a priori de posibilidad del conocimiento humano, cuya finitud se traduce precisamente en la necesidad de recurrir a la sensibilidad y en la consiguiente imposibilidad de penetrar intelectualmente de una manera directa en los seres ónticamente existentes, viéndose el hombre por el contrario obligado a concebir originariamente el ser común inexistente. Este se concibe, por tanto, no sólo con la razón pura - como terminó por creer Hegel, de acuerdo en esto con todo racionalismo-, sino con la imaginación trascendental, es decir con la inteligencia necesitada de la sensibilidad y en unión originaria o trascendental, simple o inmediata y, por tanto, indisoluble con ella, unión anterior o previa a cualquier concepción determinada 
de los diversos seres o de los diversos entes. Semejante potencia intermedia no es otra que la potencia cognoscitiva humana como tal (überbaupt) o como potencia del primer idealismo" (Inciarte, 2012: 27-28).

Esta forma de sensibilidad, moral pero no moralizante, es la que se pone en juego en el arte. La sensibilidad de la verdad se advierte —en este casoen un proceso de concentración en el que el sensibus funciona como una síntesis orgánica de idea y forma, como un punto de vista que — como tal— es subjetivo, pero — valga la insistencia—no arbitrario:

Ya desde el principio, el arte en el sentido actual tenía más que ver con lo que después se llamó prudentia que con ars (y, por tanto, de algún modo por cierto también más que ver con la moralidad que con la técnica —aparte de la distinción entre artes serviles y liberales—) (Inciarte, 2016: 105)

Este componente intrínsecamente ético del modo de proceder artístico impide entender el arte de un modo moralista o aleccionador que supondría dar primacía a un concepto abstracto del bien carente de sensibilidad:

El arte no tiene por cometido aleccionar. Eso sería caer otra vez en el concepto abstracto, falto de sensibilidad. Aleccionar mata al arte en su función purificadora, que no queda en la cabeza sino que llega al corazón. La dimensión ética del arte es para Tarkowskij un fin trascendente. $A$ diferencia de lo que con frecuencia se cree, la dimensión funcional del arte no reside en sugerir ideas, comunicar pensamientos, presentar ejemplos o dar ejemplo. No, el fin del arte es más bien el de preparar al hombre para la muerte, el de tocarle en lo más intimo de su ser. El arte no necesita aleccionar, en todo caso es aleccionamiento. Lo decía expresamente Gogol en una 
Maria Antonia Labrada

carta que Tardowkkij cita: Aleccionar predicando no es de mi incumbencia. El arte es ya en sí aleccionamiento. De mi incumbencia es decir las cosas con imágenes vivas, no con juicios. Yo tengo que conformar ("gestalten") la vida, no tratar de ella (Inciarte, 2016: 112-113).

La función del arte no es comunicar pensamientos o ejemplos para la vida, no es predicar o aleccionar. Esto desvirtúa su función práctica o vital. Lo que hace el arte es tocar al hombre en lo íntimo de su ser, prepararle para la muerte, y esto es lo que Gogol o Inciarte denominan aleccionamiento que no significa en este caso la acción o efecto de aleccionar. Es más bien un impulso para la acción práctica propio de quien ve con lucidez, con perspicacia. Esa clarividencia es la que proporciona la doble actividad de la imaginación trascendental y se advierte en el Stimmung, en el modo de estar en el mundo.

En el arte el contenido se resuelve en un plano formal, ético o superior. Esto es lo que se viene diciendo en el análisis del significado de la expresión sensibilidad de la verdad como opuesta al concepto. En el libro Cultura y verdad y en el epígrafe titulado Resolución del contenido en la forma analiza Inciarte las consecuencias que todo ello tiene para el diálogo entre fe y cultura. Empecemos con lo que dice sobre el arte y el concepto o contenido:

En nuestro alegato en favor del arte y la cultura, más que prescindir del qué, del contenido, se trata de hacer con éste la operación para cuya caracterización Hegel se servía del verbo alemán aufheben o del latino tollere; se trata de prescindir, sí, de él, del qué, del contenido, de eliminarlo, pero a la vez de conservarlo elevado a un plano en lo posible superior (de resolverlo) (Inciarte, 2016: 60-61). 
A lo largo del epígrafe se insiste en la idea de la resolución elevadora:

Es sólo una eliminación metódica, dirigida a obtener un fin determinado: la creación de un ambiente o atmósfera, como en los tonos o temples vitales (Stimmungen) que según Heidegger no son otra cosa que diversos modos de estar, bien o mal, en el mundo.

[...] En el arte se suele dar, una reducción de la capa racional, del qué, en comparación con las capas sensible e imaginativa: en comparación con el cómo o la sensibilidad; a veces, se habla de una reducción del concepto a favor del símbolo. También esa reducción es de tipo resolutivo: eliminativo a la vez que conservante y elevante, por ejemplo, del concepto en el símbolo (Inciarte, 2016: 62).

Esta manera de entender la sensibilidad artística, con su carácter práctico en el que la verdad es constitutiva de la sensibilidad le va a permitir a Inciarte dar una respuesta a la cuestión del diálogo entre fe y cultura.

Lo que Inciarte plantea es la compatibilidad del arte o la cultura con la fe cristiana. El autor del texto se declara sinceramente creyente; nuestro hombre (expresión en la que oculta su autoría) no sólo quería creer en Dios sino que lo quería sinceramente (Cf. Inciarte, 2016: 34), y esto se manifiesta primariamente en una tendencia iconoclasta incontenible por el terror que le causa una amenazadora conversión al mundo y la consiguiente aversión a Dios. Por eso quería destruir sus propias cartas que aún en sus tesis iconoclastas tenían evidente fuerza expresiva (es decir, poética o artística) (Cf. Inciarte, 2016: 34). 
El inicial enfrentamiento entre la sinceridad del amor a Dios de la persona creyente y las expresiones culturales va decantándose; la fe vivida no puede renunciar a la sensibilidad que se viene estudiando:

Sin el cultivo de este elemento, dicho sea no sólo de paso, la humanidad del creyente fácilmente se empobrecería de una forma que aquí también cabría calificar de presunción y haría de la fe fácilmente su caricatura, una fe muerta o, por lo menos, mortecina, incapaz de redimir lo redimible [...]. Porque en ninguna parte está dicho así, sin más, que para ser cristiano haya que hacerse necesariamente insensible a todo lo que pueda mover y conmover a las personas humanas reales, hacerse cuanto más burdo mejor en aras de una simplificación que bien podría ser otro modo de presunción, de tentar a Dios y a los hombres" (Inciarte, 2016: 6263)

Este cultivo de la sensibilidad tiene que ver con el arte y lo que le es propio: la forma, la manera, el modo de proceder, siguiendo esa elevación resolutiva a la que antes se ha hecho referencia. Es una forma de mirar en la que se deja de lado el contenido, el concepto o el qué, de lo contrario el creyente tiene el peligro de caer en una actitud iconoclasta:

Si las obras de arte se analizaran sólo desde el punto de vista de su contenido, sin sensibilidad literaria, artística, cultural: si se analizaran, pues, toscamente (digamos por un vez: como si fueran obras filosóficas; o sea, precisamente no como obras de arte, por lo menos según el concepto vulgar que se tiene de la filosofía), entonces no cabría desde el punto de vista cristiano más que rechazarlas de plano, apartar sin más la vista de ellas y, si nos apuran, destruirlas, quemarlas en la hoguera (Inciarte, 2016: 61) 
La sensibilidad para el matiz, para escuchar el tono, para ver las diferencias supone hacerse insensible al concepto, al qué:

Se trata de hacerse, por decirlo así, insensible al qué de tantos productos artísticos, incompatibles desde el punto de vista del contenido con la fe y, no digamos, con una real o supuesta cultura cristiana; de hacerse insensible a eso en su estado crudo de mero contenido, y de centrar la atención en el cómo, en la forma, en el elemento propiamente artístico; de resolver el qué, en el cómo. Sin el cultivo de este elemento la humanidad del creyente se empobrecería y haría de la fe fácilmente su caricatura" (Inciarte: 2016, 61)

Hacerse insensible al contenido significa que ese contenido no afecte a la sensibilidad. Se conoce sí con la cabeza fríamente o conceptualmente que es lo propio del contenido, sin dejar que se apodere de la sensibilidad o del corazón. La palabra corazón alude a esa confluencia entre tendencia y conocimiento que constituye el mundo de los afectos, del amor:

Aquí la sensibilidad ("lo razonable") consiste precisamente en no dejar que el mal se apodere de nuestro corazón, como se apoderó del de Adán y Eva, de Eva y de Adán, en la caída. No es el mal mismo lo que tenemos que asumir, sino lo que pueda tener de bien, que siempre algo tendrá. Porque si no hay nada perfecto en su estado natural, ni tan siquiera en un paraíso puramente terrenal, tampoco podrá haber un mal perfecto, un mal absoluto. Como decía santo Tomás: hay bien sin mal (Dios), pero no mal sin bien. En el caso de las obras de arte con un contenido inaceptable, eso significa que tenemos que conocer su contenido, en tanto lo tengan y en tanto sea relevante para su adecuada captación, únicamente 
Maria Antonia Labrada

con la cabeza. Pero nuestra sensibilidad no debe ser tan roma como para no dejarnos impresionar, emocionar y, en su caso, impregnar por la forma, por el arte ahí encerrado como un modo -en algunos casos importante, y en algunos insustituible - de tomar contacto con la realidad (Inciarte: 2016, 75-76).

No dejar que el mal se apodere del corazón, de la sensibilidad. Porque el mal - a diferencia del bien - no es absoluto y hay que verlo fríamente con la cabeza dejando que la sensibilidad se impregne de lo que pueda tener de bien, de la forma, del arte ahí encerrado.

\section{Bibliografía empleada:}

F. Inciarte, Cultura y verdad, Pamplona, Eunsa, 2016.

—, El reto del positivismo lógico, Madrid, Rialp, 1974.

-, La imaginación trascendental en la vida, el arte y la filosofía, Pamplona, Eunsa, 2012.

-, "Sobre la libertad del intelecto, de la razón y de la voluntad", en: Razón y libertad, Madrid, Rialp, 1990, pp. 284-291.

María Antonia Labrada malabrada@unav.es 